\title{
PERCEPÇÕES SOBRE A UTILIZAÇÃO DE REDES SOCIAIS PESSOAIS NO AMBIENTE DE TRABALHO
}

\author{
PERCEPTIONS ON THE USE OF PERSONAL SOCIAL \\ NETWORKS IN THE WORK ENVIRONMENT
}

\section{PERCEPCIONES SOBRE LA UTILIZACIÓN DE REDES SOCIALES PERSONALES EN EL MEDIO AMBIENTE DE TRABAJO}

\author{
Vânia Gisele Bessi \\ Professora e Pesquisadora do Mestrado Profissional em \\ Indústria Criativa da Universidade Feevale, Brasil / \\ Doutora em Administração, Brasil \\ vania@feevale.br
}

\section{Cáren Maria da Rosa Rinker}

Coordenadora de Registro Acadêmico da Universidade Feevale, Brasil / Especialista em Gestão Empresarial com Ênfase em Serviços, Brasil

carenrinker@feevale.br

\section{Dusan Schreiber \\ Professor e Coordenador do Mestrado Profissional em Indústria Criativa da Universidade Feevale, Brasil / Doutor em Administração, Brasil \\ dusan@feevale.br}

\section{Maria Cristina Bohnenberger}

Professora e Pesquisadora do Mestrado Profissional em Indústria Criativa da Universidade Feevale, Brasil / Doutora em Administração, Brasil cristin@feevale.br

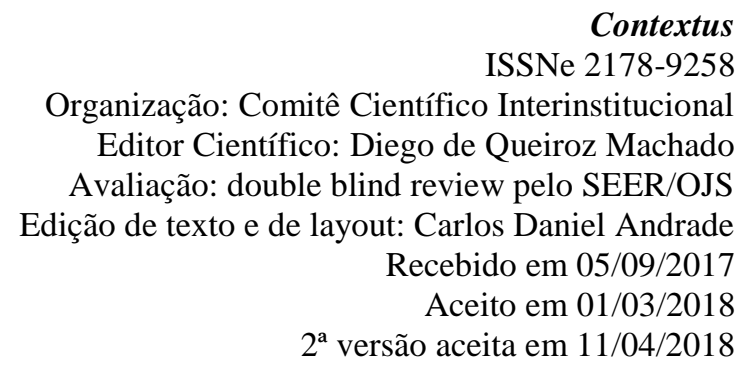

Contextus

Organização: Comitê Científico Interinstitucional Editor Científico: Diego de Queiroz Machado Avaliação: double blind review pelo SEER/OJS

Recebido em 05/09/2017 Aceito em 01/03/2018

\section{RESUMO}

Nesta pesquisa, verifica-se a percepção de gestores quanto à utilização das redes sociais virtuais por membros de suas equipes, bem como a interferência dessa utilização no ambiente de trabalho, na visão do usuário. $\mathrm{O}$ artigo foi elaborado através de uma survey com alunos de uma instituição de ensino superior em Novo Hamburgo/RS. Os dados foram coletados através de questionário estruturado, e a análise ocorreu de forma quantitativa, com a aplicação de testes estatísticos. Os resultados apontam que gestores e usuários compreendem o uso das redes sociais virtuais durante a jornada de trabalho como algo corriqueiro. Acreditam que o acesso desmedido pode interferir no desempenho das equipes. Porém, ambos apresentam a percepção de que o uso das redes sociais virtuais não apresenta reflexos negativos no desempenho do usuário, embora compreendam que as lideranças precisam manter-se atentas aos sinais emitidos pelas equipes.

Palavras-chave: Tecnologias de Informação e Comunicação. Redes Sociais. Liderança. Desempenho.

\begin{abstract}
In this research, authors seek to analyze the perception of managers regarding the use of virtual social networks by members of their teams, as well as the effect of this use on the work activities from the users' point of view. The article was prepared based on the results of a survey with the students in a higher education institution in Novo Hamburgo/RS. Data were collected by means of a structured questionnaire and were analyzed quantitatively with the use of statistical tests. The results of this study indicate that both managers and users understand that the use of social networking services at work is usual. They believe that excessive accesses can interfere on the team
\end{abstract}


performance. However, both groups have the perception that using social networking services does not have negative effects on the user's performance, although they understand that leaders need to be aware of some possible signals from their workers.

Keywords: Information and communication technologies. Social networking service. Leadership. Performance.

\section{RESUMEN}

En esta investigación se identifica la percepción de los administradores con respecto al uso de las redes sociales virtuales por miembros de sus equipos, así como el efecto de dicho uso en el escritorio, desde el punto de vista del usuario. El artículo fue elaborado a través de un levantamiento con los estudiantes en una institución de educación superior en Novo Hamburgo/RS. Los datos fueron recolectados por medio de un cuestionario estructurado, y el análisis fue cuantitativo, con la aplicación de pruebas estadísticas. Los resultados de este estudio indican que los administradores y los usuarios entienden el uso de las redes sociales virtuales durante las horas de trabajo como un lugar común, pero creen que el acceso excesivo puede interferir con el funcionamiento de los equipos. Sin embargo, ambos grupos tienen la percepción de que el uso de las redes sociales virtuales no tiene un impacto negativo en el rendimiento del usuario, aunque entiendan que los líderes tienen que estar alerta a las señales de sus equipos.

Palabras clave: Tecnologías de la información y comunicación. Redes sociales. Liderazgo. Rendimiento.

\section{INTRODUÇÃO}

A expansão das conexões de banda larga proporcionou às organizações a interligação de seus computadores, facilitando o acesso às informações e à comunicação. Porém, com isso, também passaram a ser utilizados, no ambiente organizacional, muitos meios não relacionados a ele, dentre os quais se pode incluir as redes sociais pessoais, como Facebook, Twitter e WhatsApp.

Inicialmente, a utilização das tecnologias de informação e comunicação (TICs) nas organizações era acompanhada com ferramentas que registravam tudo o que era acessado nas redes (LARIEIRA; ALBERTIN 2015). Nesse contexto, quando necessário, havia o bloqueio de determinados websites, por acreditar-se que poderiam ser prejudiciais ao desempenho do funcionário. Além disso, o gestor possuía total controle do que era realizado e acessado. Entretanto, com a evolução das tecnologias e o surgimento da conexão sem fio $(W i F i / 3 G / 4 G)$, o acesso à Internet ultrapassou as barreiras e limitações dos computadores das organizações e residências, podendo ser realizado a qualquer tempo e local a partir de celulares, notebooks, ipads e demais dispositivos móveis

(SAMBHARYA; KUMARASWAMY; BANERJEE, 2005).

Tal facilidade de acesso pode fazer com que o funcionário utilize aqueles dispositivos como forma de escapar dos bloqueios de acesso organizacional, mesmo que o monitoramento interno continue presente. $\mathrm{O}$ acesso a partir dos dispositivos móveis dificulta a intervenção e o monitoramento da organização. Diante dessa realidade, realiza-se este estudo para verificar a intensidade da utilização das 
redes sociais dentro das organizações e como os gestores a percebem.

O objetivo do artigo é verificar a percepção de gestores quanto à utilização das redes sociais por suas equipes, bem como avaliar a interferência destas no ambiente de trabalho, a partir da avaliação do usuário, buscando responder a seguinte problemática: como gestores e usuários percebem a influência do uso das redes sociais pessoais no ambiente de trabalho?

A pesquisa foi realizada com base em um survey, e a abordagem do problema ocorreu de forma quantitativa. Os dados coletados tiveram como base um questionário aplicado aos alunos de uma instituição de ensino superior (IES), em Novo Hamburgo/RS. Os respondentes foram divididos em dois grupos: os que atuam em cargos de liderança, com equipe subordinada, e os que não exercem cargos de liderança, mas atuam no mercado de trabalho e possuem perfil pessoal em redes sociais, denominados neste artigo como usuários.

A escolha por esse grupo ocorreu por conveniência, já que o objetivo foi investigar um grupo numeroso de pessoas e de diferentes níveis hierárquicos, nas organizações. A referida IES tem abrangência regional, atendendo o público de cidades do Vale do Rio dos Sinos e região metropolitana de Porto Alegre. Cabe destacar que a universidade foi uma das pioneiras na região ao oferecer a rede $\mathrm{WiFi}$ de forma livre e aberta para os estudantes. Assim, justifica-se a escolha desse grupo por ter acesso irrestrito às redes sociais pessoais nos turnos em que está na universidade e pode se sentir influenciado a acessar a rede em outros momentos do dia para se manter atualizado. A amostra se constituiu de forma não probabilística, e obtiveram-se 779 respostas.

As próximas seções deste estudo são constituídas: do referencial teórico, que contempla essencialmente a tecnologia da informação e comunicação e as redes sociais; do detalhamento do método de pesquisa; da discussão dos resultados e, por fim, das considerações finais.

\section{AS TECNOLOGIAS DA INFORMAÇÃO E COMUNICAÇÃO}

As TICs podem ser entendidas como recursos tecnológicos integrados entre si que proporcionam, por meio das funções de hardwares e softwares, a automação e a comunicação dos processos de negócios, pesquisa e aprendizagem (SAMBHARYA; KUMARASWAMY; BANERJEE, 2005; ROSA, 2006; BAILEY; FRANCIS, 2008). Para Mitra e Chaya (1996), Siqueira (2005) e Carr (2007), as TICs são ferramentas de crescimento e desenvolvimento 
organizacional, sendo utilizadas para resolver problemas relevantes do cotidiano e obter melhores serviços e produtos por menores preços.

Ao analisar a evolução das TICs, Venkatraman (1997), Broadbent e Weill (1997) e Tigre e Noronha (2013) observaram que desde a sua origem, em indústria de computadores, ocorreram diversas mudanças conceituais e estruturantes, que alteraram profundamente o perfil dos investimentos em TICs. Os autores identificaram um deslocamento da maior parte dos investimentos para o desenvolvimento do aspecto imaterial da referida tecnologia, baseada em software e ferramentas para facultar o registro e modelagem de dados e informações, propiciar a interatividade e a comunicação entre pessoas.

As TICs podem ser utilizadas de diversas maneiras, e a popularização da Internet contribuiu para o crescimento delas no meio organizacional (OLSON; BOYER, 2005; HALL, 2012). Siqueira (2005) previa que, até 2015, a utilização das TICs estaria em evidência nas organizações, e sua previsão se confirmou. Para Reichert (2009), a interatividade está visível, bastando um "click" para estar dialogando com outra pessoa em tempo real.

Segundo Larieira e Albertin (2015), o investimento em tecnologia de informação e comunicação, não apenas em hardware e software, mas também no treinamento e capacitação de pessoas, bem como em serviços de consultoria e de suporte constitui-se uma vantagem competitiva sustentável, em um mercado complexo e multifacetado. Como este tende a segmentar a massa de consumidores em nichos específicos, com peculiaridades a ser contempladas na oferta de produtos, mercadorias e serviços, as organizações necessitam de uma base de dados robusta (SAMBHARYA; KUMARASWAMY; BANERJEE, 2005). Segundo os autores, essa base de dados deve ser capaz de fornecer informações em milésimos de segundo, para subsidiar a tomada de decisão do gestor em relação a atividades de inovação ou a escolha de canais de comercialização.

Percepção similar é compartilhada por Broadbent e Weill (1997), Hall (2012) e Pinheiro e Tigre (2015), que evidenciam as contribuições das TICs para o aumento de produtividade, no âmbito organizacional. No entanto, destacam que, dependendo das métricas utilizadas para mensurar os resultados de investimentos em TICs, podem surgir interpretações que configuram o chamado "paradoxo da produtividade". É inadequado julgar de forma isolada a unidade de retorno econômico constituída de horas-produção, 
devendo ser analisada em conjunto com fatores como qualidade dos equipamentos utilizados, capacitação de colaboradores e capital intelectual (MITRA; CHAYA, 1996; CARR, 2007).

Assumpção (2003) analisou a escolha adequada da plataforma tecnológica sob o prisma da gestão da produção e de suprimentos, destacando a relevância de uma abordagem sistêmica para identificar as fragilidades da organização, que podem ser solucionadas por meio de investimentos em TICs. Nessa perspectiva, devem ser consideradas também as necessidades de outros atores envolvidos no sistema organizacional, tais como fornecedores, clientes e empresas de prestação de serviços logísticos, devido à convergência de interesses que podem ser atendidos com o compartilhamento da mesma plataforma tecnológica (CARR, 2007; HALL, 2012).

Recuero (2011) aponta que a conectividade influencia a difusão das informações. Assim, quanto mais conectada for uma rede, maiores serão as chances de uma informação ser difundida (RECUERO, 2011). Nesse sentido, salienta-se a importância que as ferramentas das TICs possuem no processo (CRUZ, 2010), pois a interação mediada via tecnologias da informação é um novo meio de construir relações (ALMEIDA, 2003; BAILEY; FRANCIS, 2008).
O crescimento tecnológico aproximou os indivíduos através de ferramentas digitais, pois faz parte do cotidiano de todos, tanto das pessoas quanto das empresas. Participar de tal evolução torna-se essencial à permanência e à sobrevivência da organização no mercado (REICHERT, 2009). Contudo, como as TICs podem ser utilizadas no meio organizacional? E quão positiva ou negativa pode ser a sua utilização? A seguir, descreve-se a utilização das TICs nesse ambiente.

\subsection{A utilização das TICs nas organizações}

Pode-se afirmar que utilizar as TICs deixou de ser meramente uma ferramenta usual no cotidiano das empresas, passando a ser essencial em suas tarefas (BAILEY; FRANCIS, 2008). No mundo do trabalho, configuram-se como importantes operadores de tempo, além de exercer grande influência na experimentação espaço-temporal dos trabalhadores (BESSI et al., 2013). As ferramentas de informação e comunicação - na busca pela superação da rigidez da produção, das relações de trabalho e das limitações espaço-temporais - proporcionaram a flexibilização dos processos de trabalho, dos mercados, produtos, dentre outros (HARVEY, 2001), 
tornando o desenvolvimento das atividades mais rápido e preciso (OLSON; BOYER, 2005 ;

SAMBHARYA;

KUMARASWAMY; BANERJEE, 2005).

Anteriormente, a maior parte da vida organizacional acontecia off-line, e apenas alguns momentos eram gastos em acesso on-line (HALL, 2012). Atualmente, com a evolução das TICs, trabalha-se em multitarefas, buscando-se dar atenção a mais de uma coisa por vez, visando atender rapidamente as tarefas executadas no dia a dia das empresas (MITRA; CHAYA, 1996; RUSHKOFF, 2012).

$\mathrm{O}$ avanço das tecnologias e a conectividade instantânea pela Internet, juntamente com a evolução dos softwares, alterou o fluxo de trabalho para um nível novo e consequentemente mais rápido (VENKATRAMAN, 1997). Em meados da década de 1980, as pessoas utilizavam computadores para criar seus conteúdos digitais e os imprimiam para trocar com outras pessoas (BROADBENT; WEILL, 1997). Em seguida, surgiu o e-mail, permitindo que as pessoas pudessem produzir seus conteúdos e trocá-los pela Internet e, por fim, chegou-se a um ponto em que máquinas interagem com máquinas sem o envolvimento humano (FRIEDMAN, 2007).

Jannuzzi, Falsarella e Sugahara (2014) evidenciaram a relevância de escolher TICs em função das necessidades organizacionais relativas a registro e modelagem de dados, para fornecer as informações de apoio ao processo decisório nas organizações. $\mathrm{O}$ super- ou subdimensionamento da estrutura, tanto em hardware quanto em software, pode impactar negativamente a produtividade organizacional, bem como a relação da empresa com os projetos que dependem de estrutura de suporte baseada em TICs (MITRA; CHAYA， 1997; BAILEY; FRANCIS, 2008; HALL, 2012).

As TICs e a Internet são, antes de mais nada, ferramentas que permitem resolver tarefas de forma mais efetiva e eficiente, pois admitem uma articulação instantânea dos integrantes da rede, garantindo maior flexibilidade e adaptabilidade e, com isso, a superioridade de um modelo organizacional no mundo globalizado (FREY, 2003; SAMBHARYA; KUMARASWAMY; BANERJEE, 2005). Essas inovações e as novas tecnologias possuem papel predominante na superação de limites, atingindo um estado mais flexível (BESSI et al., 2013). Com isso, pôde-se construir um processo organizacional rápido e interligado.

Segundo Larieira e Albertin (2015), o maior volume de investimentos em TICs, nos últimos cinco anos, ocorreu com a implantação de tecnologias de mobilidade, 
mídias sociais, computação em nuvem e big data. Dentre os fatores que orientam o processo de decisão de investir em TIC, destacam-se: i) segmento econômico; ii) porte; iii) mix de produtos, mercadorias ou serviços ofertados; iv) estratégia organizacional; v) cultura organizacional; e vi) perfil dos colaboradores que farão uso das ferramentas tecnológicas disponibilizadas.

Para Bailey e Francis (2008) e Pinheiro e Tigre (2015), a análise dos benefícios gerados pela introdução de novas TICs nas organizações não se pode mais limitar apenas à solução de gargalos na operação ou à redução de tempo para executar processos e atividades em curso. Para esses autores, a tecnologia oferece condições para modelar dados acerca do mercado no qual a organização atua, para direcionar investimentos em inovação de produtos e processos, conceber e testar novos arranjos organizacionais, implantar novos modelos de negócios e criar plataformas colaborativas com os grupos de interesse (stakeholders).

Os resultados da pesquisa conduzida por Albarracín, Erazo e Palacios (2014) junto a micro e pequenas empresas da Colômbia evidenciaram a relevância da introdução de TICs para aumento do resultado operacional. A adoção das referidas tecnologias, desde que acompanhada de capacitação, resulta em maior faturamento, pois envolve tanto uma articulação melhor das ações direcionadas para o mercado, quanto uma redução de custos operacionais, baseada no monitoramento do processo fabril $\mathrm{e}$ comercial. Outras condições favoráveis são o relacionamento interno e a comunicação, mediados por ferramentas e plataformas específicas.

As TICs são vistas como constitutivas da atual sociedade (OLSON; BOYER, 2005; HALL, 2012). Embora elas tenham auxiliado no crescimento e desenvolvimento de muitas organizações, as pessoas, por vezes, adquirem mais tecnologias na ânsia de ganhar tempo (BESSI et al., 2013), o que requer maior desempenho para compreendê-las e adaptálas às necessidades da organização. Essa ansiedade não ocorre apenas no âmbito empresarial, mas também no pessoal, com a possibilidade de aquisição de novos equipamentos que visam à busca de acessos e à inserção no meio digital.

Dispositivos com acesso a redes sociais como Facebook, Twitter, WhatsApp e e-mail transcendem a barreira da utilização esporádica e do entretenimento, tornando-se necessidades contínuas e podendo impactar na execução de tarefas diárias de trabalho (AKHTER; SIDDIQUE; MASUM, 2011). Rushkoff (2012) destaca 
que a facilidade com que uma conexão digital ocorre pode deixar as pessoas distantes e não permitir perceber o que ocorre ao lado.

\section{Young (2011) e Forest e Wood} (2012) afirmam que o acesso à Internet se torna, em alguns casos, o principal relacionamento na vida da pessoa e pode-se tornar um grande problema. Marques (2006) complementa que as redes consistem em vínculos entre pessoas ou instituições, estruturando várias situações ou configurações sociais, influenciando a troca de ideias, bens materiais, poder e informação.

\section{REDES SOCIAIS}

Uma rede social pode ser definida como "um conjunto de nós ou autores (pessoas ou organizações) ligados por relações sociais ou laços de tipos específicos. O conteúdo inclui informação, conselho ou amizade, interesses compartilhados ou pertencimentos, e tipicamente algum nível de confiança" (CRUZ, 2009, p. 20). Uma rede social digital forma-se quando um computador conecta pessoas ou organizações, provendo assim uma interação, sem ter a necessidade de estar no mesmo meio físico (RECUERO, 2011; OLLIER-MALATERRE;
O número de relacionamentos através da utilização das mídias sociais tem crescido cada vez mais (CHRISTOFIDES; MUISE; DESMARAIS, 2009). Telles (2010) informa que, no Brasil, o percentual de internautas que participam de alguma rede social chega a mais de $80 \%$, aumentando a cada dia, com pessoas que desenvolvem uma necessidade constante de se manterem conectadas.

Castells (2000) identifica dois grandes valores das comunidades virtuais: a comunicação livre e a "formação autônoma de redes", isto é, uma estrutura social composta por pessoas ou organizações, conectadas por um ou vários tipos de relações, que compartilham valores e objetivos comuns.

Segundo Donna e Silva (2014), a rede social propicia a interação entre pessoas, por meio da qual elas têm oportunidade de compartilhar ideias, percepções e interpretações da realidade. A similitude perceptiva acerca da realidade percebida contribui para a formação de comunidades, dentro da rede social, que compartilham os mesmos valores simbólicos (AKHTER; SIDDIQUE; MASUM, 2011; FOREST; WOOD, 2012). As referidas comunidades, dentro da rede social, podem constituir códigos próprios de comunicação, bem como sistema de signos,

ROTHBARD; BERG, 2013). 
como forma de se diferenciar de outros grupos sociais dentro da mesma rede.

Para Borges, Lessa e Oliveira (2014), o comportamento do indivíduo na rede social é influenciado pela sua interação com os demais indivíduos na comunidade virtual. Suas percepções e interpretação da realidade, de seus valores, bem como da compreensão do "certo" e do "errado", podem ser modificadas, contidas ou potencializadas, a partir do seu posicionamento pessoal, cognitivo e comportamental, tanto no âmbito individual, como coletivo, da internalização de valores morais e éticos, na relação que ele constrói com o "outro" (OLLIERMALATERRE; ROTHBARD; BERG, 2013).

O foco das redes sociais está na exposição pública das redes conectadas dos atores e a finalidade está relacionada à publicitação dessas redes (RECUERO, 2011). Neste contexto, destaca ainda que "um dos pontos chaves para a construção de redes sociais na Internet é, justamente, o fato de que os sistemas que as suportam permitem um maior controle das impressões que são emitidas e dadas, auxiliando na construção da reputação" (RECUERO, 2011, p.109). Para o autor, há uma interação entre a utilização de redes sociais para a apresentação da reputação e a necessidade de mantê-la atualizada e interessante.

Para Komesu (2010), a utilização de redes sociais não se refere à exibição da vida particular, mas do cotidiano e das histórias de pessoas, já que estas não exercem quaisquer atividades que lhes deem destaque social, a não ser o fato de possuírem somente seu perfil na rede. $\mathrm{Ou}$ seja, algumas pessoas utilizam as redes sociais para expor fatos de suas vidas, pois não usufruem de posição social relevante e de destaque (FOREST; WOOD, 2012). Komesu (2010) acredita que a popularização das redes sociais está relacionada também à sua utilização, pois são gratuitas e populares e por não demandam conhecimentos específicos.

Amaral, Testa e Luciano (2013) destacam que sites de redes sociais, tais como o Facebook, LinkedIn e MySpace, permitem que os indivíduos criem perfis de exibição pessoal estabelecendo e mantendo conexões com outros indivíduos. Entretanto estas interações também podem ter propósitos específicos, como contatos profissionais, relacionamentos afetivos ou conectar-se com pessoas de interesses comuns (CHRISTOFIDES; MUISE; DESMARAIS, 2009; HAHN; SCHERER; BASSO; SANTOS, 2016).

As organizações também já perceberam que podem obter diversos 
benefícios ao constituir redes sociais virtuais organizacionais (BOBSIN; HOPPEN, 2014). Dentre as vantagens os autores destacam a constituição de uma estrutura interna, com interface amigável, para o compartilhamento do conhecimento, contribuindo para reduzir os índices de retrabalho e redução de riscos de tomada de decisão equivocada. No entanto, por meio do estudo empírico constataram que a adoção e utilização das redes sociais virtuais corporativas não pode ser imposta pela alta gestão (BOBSIN; HOPPEN, 2014). A rede social dentro da organização tende a ser internalizada e passa a fazer parte do repertório de elementos constitutivos da cultura organizacional, assumindo um comportamento orgânico e refratário à manipulação pelos atores sociais que atuam na organização por meio de relações de poder formalmente constituídas. Por esse motivo as redes sociais virtuais organizacionais costumam desconstruir as estruturas organizacionais hierarquizadas (SODA; ZAHEER, 2012).

$$
\text { Consideradas como grande }
$$
contribuinte para as organizações, as TICs possuem enorme adesão e impacto ao meio organizacional (CROSS; BORGATTI; PARKER, 2002; AKHTER; SIDDIQUE; MASUM, 2011). A utilização das redes de comunicação digital e a necessidade constante de se manter conectado demonstra notavelmente um crescimento do uso dentro das empresas nos últimos anos (YOUNG, 2011).

Para Rosa (2007), o cenário competitivo está criando pessoas que estão buscando relacionamentos de todos os tipos no mundo virtual e as empresas devem estar atentas para essa migração, pois o impacto sobre o desempenho do funcionário pode ser grande. A comunicação virtual pode lhes parecer mais segura e fácil, contudo, pode atrapalhar nas relações de trabalho (YOUNG, 2011; SODA; ZAHEER, 2012). O domínio digital está permanente e o livre experimento dos jovens está sendo trocado pela fácil e rápida conexão com o mundo virtual (RUSHKOFF, 2012). As redes sociais fazem parte deste domínio digital e pode-se dizer que estão em constante utilização no meio organizacional (CROSS; BORGATTI; PARKER, 2002).

Embora o crescimento das redes sociais na Internet ocorra no mundo todo, o Brasil se destaca como um dos principais países a utilizar tais ferramentas. Conforme o relatório do Comitê Gestor da Internet (CGI) no Brasil, o maior usuário em termos de tempo e conexão é o brasileiro, o que demonstra que a Internet no país é um forte instrumento de socialização (AMARAL, TESTA e LUCIANO, 2013). As estimativas indicam que dois terços da população on-line mundial participam de 
sites de redes sociais virtuais. No Brasil essa utilização é ainda mais intensa, onde os pesquisados gastam em média $23 \%$ do tempo on-line, acessando redes sociais (CRUZ, 2009).

Esta intensa utilização, somada as tecnologias disponíveis e o fácil acesso à Internet através de celulares, tablets, notebooks, pode contribuir para distração e baixo desempenho dos empregados. Segundo Rushkoff (2012, pág. 150), "seremos conduzidos em direção a atividades que ajudam a nos distrair dos desafios". A inserção em redes é determinante para o compartilhamento da informação e do conhecimento, visto que estes espaços valorizam 0 compartilhamento de informações e podem auxiliar na construção do conhecimento (CRUZ，2009; GULATI; SILVESTRI, 2013). Young (2011, p. 50) destaca um ponto importante nesta questão: "na medida em que as corporações dependem de sistemas de gerenciamento da informação para praticamente todos os aspectos de seu negócio, o abuso da Internet por parte dos empregados [...] está se tornando uma possível epidemia nas empresas".

Embora a sociedade e as organizações reajam de forma diferente a essas tecnologias, é preciso estar atento à influência que estas possuem no desempenho dos funcionários de uma organização, e o quanto podem utilizar positivamente visando o aumento da produtividade, ou ainda, identificar a necessidade de bloqueio. Contudo, sabe-se que isto não limita a utilização, pois mesmo bloqueado no trabalho, o acesso através de dispositivos móveis permanece.

Diante desse cenário, acredita-se que a utilização das redes sociais pessoais durante o expediente de trabalho tenha reflexos no ambiente e no desempenho organizacional, o que reforça a necessidade de aprofundar estudos sobre a temática. A próxima seção apresenta os procedimentos metodológicos do estudo.

\section{PROCEDIMENTOS METODOLÓGICOS}

Este estudo efetivou-se mediante a aplicação de uma pesquisa survey, que consiste em entrevistas baseadas em um questionário estruturado. Tal método visa obter informações sobre comportamento, intenções, atitudes, percepções, motivações e estilo de vida (MALHOTRA, 2001).

O universo da pesquisa se constituiu de alunos de uma IES. A amostra foi não probabilística por conveniência, com base no número de respondentes da pesquisa. A amostra por conveniência geralmente é utilizada em pesquisas exploratórias para gerar hipóteses (MALHOTRA, 2001). 
Para a coleta de dados, desenvolveuse um questionário com 51 perguntas fechadas, das quais: i) 17 questões iniciais foram respondidas por todos; ii) 14 questões foram respondidas por pessoas que exerciam cargo de liderança, tendo subordinados sob seu comando; e, iii) 20 questões foram respondidas por aqueles que não exerciam nenhum cargo de liderança e foram considerados como usuários de redes sociais.

Os questionários foram encaminhados via e-mail à base de dados de alunos matriculados na graduação e pósgraduação, pelo Centro de Pesquisa e Planejamento da IES onde os dados foram coletados. Foram obtidas 1.202 respostas, sendo que destas, 152 foram consideradas inválidas por falhas no sistema de coleta. Dos 1.050 questionários considerados válidos, excluíram-se 232 por não estarem ativos no mercado de trabalho, chegando-se ao total de 818 questionários. Ainda, foram excluídos 39 questionários pois foram respondidos por pessoas que atuavam no mercado de trabalho, porém não possuíam rede social. Ao final, chegou-se a 779 respondentes, dos quais 191 eram gestores (possuindo pessoas subordinadas) e 588 usuários de redes sociais.

A análise dos dados ocorreu de forma quantitativa. Buscando identificar a existência de correlação entre os resultados obtidos e comparação das questões escalares com características do perfil foram utilizados testes não paramétricos utilizando o software SPSS 22.0. Para testar amostras aleatórias independentes em mais de duas categorias (FREUND, 2000), utilizou-se o teste Kruskal-Wallis. O teste de Mann-Whitney, uma alternativa não paramétrica para teste de duas amostras (FREUND, 2000), foi utilizado para avaliar as respostas com apenas duas categorias. Para identificar tanto a associação entre cargo de liderança e frequência de utilização, quanto a permissão de acesso a redes sociais dentro das organizações, foi aplicado o teste Qui-Quadrado. Este último teste é aplicado, segundo Downing (1999, p. 257), para "testar se dois fatores são independentes". A inferência estatística utilizada foi realizada considerando um nível de significância de 5\%.

A seguir, apresentam-se a análise e a discussão dos resultados obtidos através dos dados coletados.

\section{APRESENTAÇÃO DISCUSSÃO DOS RESULTADOS}

$\mathbf{E}$

Redes de comunicação digital como Facebook, Twitter e WhatsApp tornam-se cada dia mais frequentes dentro das organizações, para o que contribuem a facilidade de acesso e as tecnologias 
disponíveis. Buscando identificar como se dá o seu uso no meio organizacional, aplicou-se uma pesquisa respondida por 779 alunos de uma IES localizada na região metropolitana de Porto Alegre/RS, sendo $58,3 \%$ dos respondentes do sexo feminino (454 respondentes) e $41,7 \%$, sexo masculino (325 respondentes). A maioria dos respondentes possui idade entre 21 e 25 anos $(38,9 \%)$, seguida pelo percentual de $20,5 \%$, que possui entre 26 e 30 anos. Essas faixas de idade são compatíveis com o perfil do estudante de ensino superior, público alvo deste estudo.

Utilizou-se a escala definida pelo SEBRAE (2015) para divisão e classificação do porte das empresas, empresas, para classificar as empresas de atuação dos respondentes. A Tabela 1 apresenta o porte das empresas em que os respondentes atuam.

Tabela 1 - Respondentes por porte

\begin{tabular}{lll}
\hline Qual o número de funcionários da empresa? & Freq. & $\%$ \\
\hline Microempresas - Até 19 funcionários & 240 & $30,8 \%$ \\
Pequenas empresas - De 20 a 99 funcionários & 174 & $22,3 \%$ \\
Médias empresas - De 100 a 499 funcionários & 91 & $11,7 \%$ \\
Grandes Empresas - Mais de 500 funcionários & 274 & $35,2 \%$ \\
\hline TOTAL & $\mathbf{7 7 9}$ & $\mathbf{1 0 0 \%}$ \\
\hline
\end{tabular}

Fonte: Dados da pesquisa/2016.

Dentre as organizações, sejam elas microempresas, pequenas, médias ou de grande porte, o perfil de usuários de redes sociais é constatado em todas. Contudo, é possível observar que a maioria dos respondentes atua em microempresas e em empresas de grande porte, sendo 30,8\% e $35,2 \%$ respectivamente.

Dentre os entrevistados as redes mais acessadas são o Facebook com 97,6\%, WhatsApp com 84,3\%, Instagram com $54,6 \%$ e Twitter com $30,2 \%$. Os resultados foram considerados com base nos itens selecionados, pois cada respondente poderia selecionar mais de uma rede social. A utilização dessas redes sociais ocorre com maior frequência através do celular $(86,9 \%$ dos respondentes), seguido de notebook (67,4\% dos respondentes), computador $(50,9 \%$ dos respondentes) e tablet $(17,3 \%$ dos respondentes). $\mathrm{O}$ telefone celular, considerado um grande meio de comunicação, deixou de ser apenas para uso de ligações, passando a assumir papel fundamental para acesso às redes sociais disponíveis, bem como demais aplicativos de entretenimento e diversão. Este uso, segundo Rushkoff (2012), pode direcionar para a distração dos funcionários durante a execução da sua atividade de trabalho.

Questionados se o seu local de trabalho permite o acesso a redes sociais nos 
computadores da empresa, 54,4\% dos respondentes (412 pessoas) indicaram que a empresa não permite o acesso. Entretanto 90,1\% dos respondentes admitiram que acessam seus perfis através de dispositivos móveis durante o horário de trabalho. Este dado justifica o uso do celular como dispositivo mais citado pelos usuários, pois a empresa pode realizar bloqueios em sua rede, mas o acesso através de celulares, com Internet independente, não pode ser gerenciado ou controlado pela gestão.

\subsection{Percepção dos gestores quanto ao} acesso às redes sociais por parte dos subordinados

O uso de redes sociais transcende a barreira da utilização esporádica e de entretenimento e pode vir a impactar na execução das tarefas diárias de trabalho do indivíduo. A facilidade com que uma conexão digital ocorre pode deixar as pessoas distantes e não lhes permitir perceber o que ocorre ao lado (RUSHKOFF，2012). A percepção dos gestores pode contribuir para identificar tanto o uso das redes sociais pessoais, medidas que auxiliem no desempenho do funcionário em suas atividades.

Para esta análise, foram considerados como gestores os respondentes que afirmaram ter pessoas subordinadas a si no ambiente de trabalho. Estes responderam a 14 perguntas visando identificar a percepção quanto ao acesso às redes sociais durante a jornada de trabalho. A Tabela 2 apresenta a percepção dos gestores quanto ao tempo de acesso as redes sociais por sua equipe.

Tabela 2 - Tempo que sua equipe realiza verificações/atualizações

\begin{tabular}{lll}
\hline $\begin{array}{l}\text { Quantifique o tempo (por dia) em que você percebe que } \\
\text { sua equipe realiza verificações/atualizações em seu perfil em } \\
\text { redes sociais, durante a jornada de trabalho: }\end{array}$ & Freq. & $\%$ \\
\hline Não utiliza & & \\
Menos de $1 \mathrm{~h}$ & 80 & $26,2 \%$ \\
De $1 \mathrm{~h}$ a $2 \mathrm{~h}$ & 43 & $42,4 \%$ \\
De $3 \mathrm{~h}$ a $5 \mathrm{~h}$ & 7 & $3,7 \%$ \\
Mais de 5 horas & 10 & $5,2 \%$ \\
\hline TOTAL & $\mathbf{1 9 1}$ & $\mathbf{1 0 0 \%}$ \\
\hline
\end{tabular}

Fonte: Dados da pesquisa/2016.

A maior concentração de respostas demonstra que a percepção quanto à utilização é de que esta ocorre menos de 1 hora por dia $(42,4 \%$ dos gestores $)$. Na sequência, 22,5\% dos gestores acreditam que a utilização ocorre entre 1 e 2 horas por dia, enquanto $26,2 \%$ dos respondentes não percebem essa utilização.

Rushkoff (2012) destaca que, dentro das organizações, com a evolução das TICs, trabalha-se com multitarefas. Com isso, os funcionários, além de realizar suas 
atividades, acabam por acessar também as suas redes sociais, que podem impactar ou não no desempenho. Podem-se analisar os resultados através de dois pontos: i) redes sociais são utilizadas para o trabalho, o que faz com que a sua percepção em relação ao uso seja minimizada, ou ainda, ii) esse uso não interfere nos resultados do funcionário, ou é quase imperceptível não apresentando impacto na realização da atividade.

Buscando identificar ainda uma possível diferença entre o porte de cada empresa e a percepção dos gestores em relação à frequência de utilização e acesso as redes sociais no ambiente de trabalho, foi aplicado o teste Kruskal-Wallis, porém não se encontrou nenhuma diferença significativa nas respostas dos gestores.

A Tabela 3 amplia a análise sobre a percepção dos gestores, quanto à utilização de redes sociais no ambiente organizacional.

Tabela 3 - Percepção da utilização das redes sociais no ambiente organizacional

\begin{tabular}{|c|c|c|c|c|c|c|}
\hline Com que frequência você... & Nunca & Raramente & $\begin{array}{l}\text { Às } \\
\text { vezes }\end{array}$ & Frequentemente & Sempre & $\begin{array}{l}\text { Não } \\
\text { sei/Não } \\
\text { se aplica }\end{array}$ \\
\hline $\begin{array}{l}\text { Percebe que o funcionário se } \\
\text { mantém conectado às redes sociais } \\
\text { por muito tempo ao longo da } \\
\text { jornada de trabalho }\end{array}$ & $10,0 \%$ & $14,0 \%$ & $36,7 \%$ & $25,1 \%$ & $7,9 \%$ & $6,3 \%$ \\
\hline $\begin{array}{l}\text { Percebe que seus funcionários } \\
\text { costumam deixar de lado tarefas } \\
\text { do trabalho para conectar-se a suas } \\
\text { redes. }\end{array}$ & $20,4 \%$ & $38,2 \%$ & $29,8 \%$ & $6,3 \%$ & $1,6 \%$ & $3,7 \%$ \\
\hline $\begin{array}{l}\text { Percebe que seus funcionários } \\
\text { costumam trocar seus horários de } \\
\text { intervalo para ficarem conectados } \\
\text { às redes sociais. }\end{array}$ & $29,8 \%$ & $20,4 \%$ & $23,6 \%$ & $19,4 \%$ & $3,1 \%$ & $3,7 \%$ \\
\hline
\end{tabular}

Observa-se que $\quad 36,7 \%$ dos respondentes percebem que os funcionários às vezes estão conectados em redes sociais durante $o$ expediente, ratificando a percepção já demonstrada anteriormente. Os gestores avaliaram que seus funcionários de forma geral não costumam trocar seus intervalos ou deixar de lado tarefas para acessar redes sociais. Observase que $7,9 \%$ dos gestores avaliam que o funcionário se mantém sempre conectado,
$3,1 \%$ dos gestores acreditam que os subordinados trocam seus intervalos para ficarem acessando seus perfis e apenas $1,6 \%$ dos funcionários percebe que os colegas deixam de lado tarefas de seu dia a dia.

Embora o acesso possa ser avaliado como moderado pode ocasionar um impacto no desempenho do funcionário. Recuero (2011) aponta que a conectividade 
influencia na difusão das informações, e que os acessos, frequentes ou esporádicos, podem impactar no desempenho dos funcionários. Young (2011) destaca ainda que a utilização da Internet está se revelando um problema de produtividade, e consequentemente impactando no desempenho dos funcionários.

A Tabela 4 apresenta a concordância dos gestores quanto à utilização e o impacto das redes sociais e medidas que acreditam ser necessárias para solucionar casos de uso abusivo.

Tabela 4 - Utilização e impacto das redes sociais no ambiente organizacional

\begin{tabular}{|c|c|c|c|c|c|c|}
\hline $\begin{array}{l}\text { Quanto às organizações } \\
\text { hoje em dia, você } \\
\text { concorda que... }\end{array}$ & $\begin{array}{l}\text { Discordo } \\
\text { totalmente }\end{array}$ & $\begin{array}{l}\text { Discordo } \\
\text { parcialmente }\end{array}$ & Concordo & $\begin{array}{l}\text { Concordo } \\
\text { parcialmente }\end{array}$ & $\begin{array}{l}\text { Concordo } \\
\text { totalmente }\end{array}$ & $\begin{array}{l}\text { Não } \\
\text { sei/ } \\
\text { não } \\
\text { se } \\
\text { aplica }\end{array}$ \\
\hline $\begin{array}{lr}\text { O desempenho do } \\
\text { funcionário } & \text { impacta } \\
\text { diretamente } & \text { nos } \\
\text { objetivos } & \text { da } \\
\text { organização? } & \end{array}$ & $0,5 \%$ & $2,1 \%$ & $34,6 \%$ & $12,0 \%$ & $49,2 \%$ & $1,6 \%$ \\
\hline $\begin{array}{l}\text { A utilização de redes } \\
\text { sociais no ambiente de } \\
\text { trabalho impacta no } \\
\text { desempenho dos } \\
\text { funcionários? }\end{array}$ & $1,6 \%$ & $14,1 \%$ & $28,3 \%$ & $24,6 \%$ & $28,8 \%$ & $2,6 \%$ \\
\hline $\begin{array}{l}\text { As empresas devem } \\
\text { bloquear os acessos, } \\
\text { mesmo sabendo que } \\
\text { existe a possibilidade } \\
\text { de acesso fora da rede } \\
\text { organizacional? }\end{array}$ & $18,3 \%$ & $26,7 \%$ & $18,9 \%$ & $21,5 \%$ & $13,6 \%$ & $1,0 \%$ \\
\hline $\begin{array}{l}\text { As organizações, além } \\
\text { de bloquear, devem } \\
\text { solicitar aos } \\
\text { funcionários que } \\
\text { entreguem ou guardem } \\
\text { seus aparelhos } \\
\text { eletrônicos ao longo da } \\
\text { jornada de trabalho? }\end{array}$ & $51,8 \%$ & $17,3 \%$ & $9,4 \%$ & $11,0 \%$ & $8,9 \%$ & $1,6 \%$ \\
\hline $\begin{array}{l}\text { As organizações não } \\
\text { devem bloquear, mas } \\
\text { sim fazer programas de } \\
\text { conscientização para o } \\
\text { correto uso ao longo da } \\
\text { jornada de trabalho? }\end{array}$ & $5,8 \%$ & $7,9 \%$ & $35,6 \%$ & $12,0 \%$ & $37,2 \%$ & $1,5 \%$ \\
\hline $\begin{array}{l}\text { O funcionário precisa } \\
\text { ter metas para cumprir, } \\
\text { e estar ciente das } \\
\text { consequências, caso } \\
\text { não atinja aquelas } \\
\text { devido ao tempo de } \\
\text { utilização de redes } \\
\text { sociais? }\end{array}$ & $3,7 \%$ & $1,1 \%$ & $39,8 \%$ & $12,6 \%$ & $39,8 \%$ & $3,0 \%$ \\
\hline
\end{tabular}

Fonte: Dados da pesquisa/2016. 
Evidencia-se que $49,2 \%$ dos respondentes, que são gestores, concordam totalmente que o desempenho do funcionário impacta diretamente nos objetivos da organização e $28,8 \%$ concordam que a utilização de redes sociais impacta no desempenho dos funcionários. Chama atenção que $0,5 \%$ dos gestores discorda totalmente que o desempenho do funcionário impacta nos objetivos da organização. A percepção dos gestores permite a interpretação de que o uso e acesso a redes sociais impacta diretamente nos resultados de seus subordinados, e como visto anteriormente, a maioria dos acessos ocorre através de dispositivos móveis. Atitudes para o uso descontrolado são avaliadas pelos gestores como possíveis. Dentre as opções, 13,6\% dos gestores concordam totalmente que as organizações devem bloquear os acessos e $8,9 \%$ dos gestores optariam em recolher os aparelhos de seus funcionários antes de iniciar a jornada de trabalho. Contudo, uma grande parte dos gestores $(37,2 \%)$ entende que deve haver programas de conscientização quanto ao uso. Esta percepção aparece entre $37,2 \%$ dos respondentes, e 39,8\% dos gestores ainda entendem que a melhor opção é estabelecer metas e objetivos aos funcionários.

Como ressaltam Young (2011) e Soda e Zaheer (2012), a comunicação virtual, utilizada excessivamente pelas pessoas no ambiente de trabalho, pode afetar as relações entre colegas, uma vez que cria situações paralelas àquelas que são específicas dos assuntos relacionados ao trabalho. Esse mundo digital pode se tornar uma válvula de escape para que os usuários restabeleçam energias para o trabalho, porém esse é um discernimento que exige maturidade e um perfil comportamental consciente de suas responsabilidades.

Medidas radicais muitas vezes acabam se tornando necessárias, mas aplicá-las deve ser o último recurso de uma organização, atitudes como proporcionar conscientizações, destacar a importância do funcionário para a organização e fazer com que saiba que possui e deve cumprir metas e objetivos avalia-se ser a melhor saída para esta situação. Aplicando o teste MannWhitney é possível identificar variação entre a percepção de gestores que possuem redes sociais e os que não possuem redes sociais $(\mathrm{p}<0,05)$. A Tabela 5 apresenta a significância encontrada nas questões. 
Tabela 5 - Teste Mann-Whitney

\begin{tabular}{ll}
\hline Estatísticas de teste: & $\begin{array}{l}\text { Significância } \\
(\mathrm{p}<0,05)\end{array}$ \\
\hline $\begin{array}{l}\text { Que as empresas devem bloquear os acessos, mesmo sabendo que existe a possibilidade de } \\
\text { acesso fora da rede organizacional? }\end{array}$ & 0,002 \\
$\begin{array}{l}\text { Que as organizações, além de bloquear, devem solicitar aos funcionários que entreguem ou } \\
\text { guardem seus aparelhos eletrônicos ao longo da jornada de trabalho? }\end{array}$ & 0,001 \\
$\begin{array}{l}\text { Que as organizações não devem bloquear, mas sim fazer programas de conscientização para } \\
\text { o correto uso ao longo da jornada de trabalho? }\end{array}$ & 0,007 \\
\hline
\end{tabular}

Fonte: Dados da pesquisa/2016.

Avaliando medidas cabíveis para o uso dentro das organizações, gestores que não possuem redes sociais são mais radicais e entendem que deve haver bloqueio de acessos e ainda solicitar os aparelhos aos funcionários. Já os gestores que possuem redes sociais são menos opressivos e entendem que deve haver uma conscientização sobre o uso ao longo da jornada de trabalho.

Questionados sobre como avaliam a equipe, na Tabela 6 é possível verificar a avaliação que o gestor faz quanto a sua equipe e o desempenho que a mesma apresenta atualmente.

Tabela 6 - Avaliação da equipe gerenciada considerando a utilização de redes sociais no ambiente organizacional

\begin{tabular}{|c|c|c|c|c|c|c|}
\hline Como você avalia... & Irregular & Regular & Suficiente & Bom & $\begin{array}{l}\text { Muito } \\
\text { bom }\end{array}$ & $\begin{array}{l}\text { Não } \\
\text { sei/Não } \\
\text { se aplica }\end{array}$ \\
\hline $\begin{array}{l}\text {... o desempenho e o desenvolvimento } \\
\text { profissional de sua equipe, mesmo } \\
\text { utilizando as redes sociais na jornada } \\
\text { de trabalho? }\end{array}$ & $4,7 \%$ & $12,0 \%$ & $12,6 \%$ & $39,8 \%$ & $22,0 \%$ & $8,9 \%$ \\
\hline $\begin{array}{l}\text {... o grau de concentração de seus } \\
\text { funcionários para a realização de suas } \\
\text { atividades e a participação de seus } \\
\text { funcionários no cumprimento dos } \\
\text { objetivos da organização? }\end{array}$ & $4,7 \%$ & $11,0 \%$ & $17,3 \%$ & $42,4 \%$ & $22,5 \%$ & $2,1 \%$ \\
\hline
\end{tabular}

Fonte: Dados da pesquisa/2016.

Os gestores em sua maioria avaliam o desempenho de sua equipe entre bom e muito bom, $39,8 \%$ e $22 \%$ respectivamente, e apenas $4,7 \%$ avaliaram como irregular. $\mathrm{O}$ grau de concentração dos funcionários foi considerado bom $(42,4 \%)$. No cenário competitivo, identificam-se pessoas que estão à procura de relacionamentos de todos os tipos no mundo virtual, e Rosa (2007) salienta que é preciso que as empresas permaneçam atentas a estes movimentos, pois o impacto sobre o desempenho do funcionário pode ser significativo. SCHNOOR apud CRUZ (2009) destaca também as estimativas de que dois terços da população on-line mundial participam de sites de redes sociais virtuais. No Brasil essa utilização é ainda mais intensa, e é preciso 
que as organizações avaliem sua utilização por parte de seus funcionários.

\subsection{Percepção de usuários quanto a utilização de redes sociais no ambiente organizacional}

Visando identificar a percepção de usuários de redes sociais, apresenta-se a visão de 588 respondentes sobre o acesso a redes sociais no ambiente organizacional e o impacto causado em seu desempenho. É importante ressaltar que, para este estudo considerou-se como usuário aqueles responderam que responderam negativamente à questão sobre se havia pessoas sob sua supervisão no ambiente de trabalho. A Tabela 7 apresenta os resultados quanto à frequência com que este grupo de pesquisados costuma acessar seus perfis durante a jornada de trabalho.

Tabela 7 - Acesso e atualização do perfil durante a jornada de trabalho

\begin{tabular}{lll}
\hline $\begin{array}{l}\text { Dentro da sua jornada de trabalho, você costuma } \\
\text { consultar e atualizar seu perfil em redes sociais } \\
\text { com que frequência? }\end{array}$ & Freq. & $\%$ \\
\hline Raramente & & $35,4 \%$ \\
Nunca & 208 & $31,5 \%$ \\
Às vezes & 185 & $25,5 \%$ \\
Quase sempre & 150 & $4,9 \%$ \\
Sempre & 29 & $2,7 \%$ \\
\hline TOTAL & 16 & $\mathbf{1 0 0 \%}$ \\
\hline
\end{tabular}

Fonte: Dados da pesquisa/2016.

Constatou-se que $35,4 \%$ dos respondentes afirmam que raramente acessam seus perfis durante a jornada de trabalho, e apenas $4,9 \%$ dos respondentes informaram que quase sempre realizam este acesso. Ainda 25,5\% dos respondentes alegam que às vezes acessam suas redes sociais durante a jornada de trabalho. Questionados também sobre os locais que costumam acessar suas redes, os usuários indicaram os locais utilizados, conforme apresentado na Tabela 8.

Tabela 8 - Locais de acesso às redes sociais

\begin{tabular}{|c|c|c|c|c|c|c|}
\hline $\begin{array}{l}\text { Você acessa, ao longo do } \\
\text { dia, as redes sociais... }\end{array}$ & Nunca & Raramente & $\begin{array}{l}\text { Às } \\
\text { vezes }\end{array}$ & Frequentemente & Sempre & $\begin{array}{l}\text { Não } \\
\text { sei/Não } \\
\text { se aplica }\end{array}$ \\
\hline Em casa & $0,7 \%$ & $11,4 \%$ & $25,7 \%$ & $34,4 \%$ & $27,6 \%$ & $0,2 \%$ \\
\hline No trabalho & $21,8 \%$ & $29,3 \%$ & $28,7 \%$ & $13,3 \%$ & $6,5 \%$ & $0,4 \%$ \\
\hline Em equipamentos de amigos & $65,1 \%$ & $27,4 \%$ & $6,5 \%$ & $0,7 \%$ & $0,0 \%$ & $0,3 \%$ \\
\hline Na escola/faculdade & $6,6 \%$ & $16,5 \%$ & $37,9 \%$ & $27,7 \%$ & $10,9 \%$ & $0,4 \%$ \\
\hline Em seus dispositivos móveis & $5,4 \%$ & $7,7 \%$ & $16,0 \%$ & $29,6 \%$ & $40,8 \%$ & $0,5 \%$ \\
\hline $\begin{array}{l}\text { Nos computadores de sua } \\
\text { empresa }\end{array}$ & $55,6 \%$ & $17,4 \%$ & $13,4 \%$ & $8,8 \%$ & $4,3 \%$ & $0,5 \%$ \\
\hline
\end{tabular}

Fonte: Dados da pesquisa/2016. 
Entre as opções de acesso, 40,8\% informaram que costumam acessar suas redes através de dispositivos móveis, sendo que o segundo local mais utilizado é em casa, 27,6\%, em seus computadores particulares. E ainda 55,6\% afirmam que nunca acessam seu perfil nos computadores da empresa, neste aspecto surge o questionamento se a empresa possa ter realizado o bloqueio dos sites das redes sociais para coibir o acesso dos empregados. A Tabela 9 apresenta o tempo em que o usuário se percebe conectado as redes sociais no local de trabalho.

Tabela 9 - Tempo em que sua equipe realiza verificações/atualizações

\begin{tabular}{lll}
\hline $\begin{array}{l}\text { Quantifique o tempo (por dia) em que } \\
\text { você realiza verificações/atualizações em seu perfil } \\
\text { em redes sociais durante a jornada de trabalho. }\end{array}$ & Freq. & $\%$ \\
\hline Não utilizo & 150 & $25,5 \%$ \\
Menos de $1 \mathrm{~h}$ & 298 & $50,7 \%$ \\
De $1 \mathrm{~h}$ a $2 \mathrm{~h}$ & 102 & $17,4 \%$ \\
De $3 \mathrm{~h}$ a $5 \mathrm{~h}$ & 28 & $4,8 \%$ \\
Mais de $5 \mathrm{~h}$ & 10 & $1,6 \%$ \\
\hline TOTAL & $\mathbf{5 8 8}$ & $\mathbf{1 0 0 \%}$ \\
\hline
\end{tabular}

Fonte: Dados da pesquisa/2016.

Menos de 1 hora, este é o tempo que a maioria dos respondentes avalia o seu uso durante a jornada de trabalho $(50,7 \%$ dos respondentes) e apenas $1,7 \%$ dos pesquisados afirmaram que utilizam o acesso por mais de 5 horas. É possível observar que o usuário avalia sua utilização como sendo pouco frequente, e que possivelmente este uso não reflete em seu desempenho, como demonstra a seguir a Tabela 10, apresentando a avaliação do usuário em relação ao seu desempenho.

Tabela 10 - Avaliação do usuário

\begin{tabular}{|c|c|c|c|c|c|c|}
\hline Como você avalia... & Insuficiente & Regular & Suficiente & Bom & $\begin{array}{l}\text { Muito } \\
\text { bom }\end{array}$ & $\begin{array}{l}\text { Não } \\
\text { sei/Não } \\
\text { se aplica }\end{array}$ \\
\hline $\begin{array}{l}\text { Seu desempenho profissional, } \\
\text { mesmo utilizando as redes } \\
\text { sociais na jornada de trabalho. }\end{array}$ & $0,5 \%$ & $2,0 \%$ & $3,9 \%$ & $21,6 \%$ & $51,2 \%$ & $20,8 \%$ \\
\hline $\begin{array}{l}\text { Seu grau de concentração para } \\
\text { realização de suas atividades e } \\
\text { sua participação no } \\
\text { cumprimento dos objetivos da } \\
\text { organização. }\end{array}$ & $0,2 \%$ & $1,9 \%$ & $6,0 \%$ & $28,7 \%$ & $55,2 \%$ & $8,0 \%$ \\
\hline $\begin{array}{l}\text { Seu desenvolvimento como } \\
\text { profissional, considerando a } \\
\text { interferência das redes sociais. }\end{array}$ & $0,5 \%$ & $2,2 \%$ & $4,3 \%$ & $28,1 \%$ & $47,2 \%$ & $17,7 \%$ \\
\hline
\end{tabular}

Fonte: Dados da pesquisa/2016. 
Os usuários avaliam seu desempenho profissional, mesmo utilizando as redes sociais durante a jornada de trabalho, como muito bom $(51,2 \%)$. Avaliam ainda como muito bom o seu grau de concentração e o seu desenvolvimento como profissional. Sua percepção é de que o acesso às redes sociais durante a jornada de trabalho não gera impacto sobre eles ou sobre as atividades que estão desenvolvendo. Contudo, mais de $20 \%$ não souberam ou não quiseram opinar sobre o seu desempenho profissional.

Buscando realizar ainda a auto avalição do usuário, as tabelas a seguir procuram identificar a percepção quanto à frequência do uso e o impacto no dia a dia. A Tabela 11 apresenta a auto avaliação.

Tabela 11 - A frequência de acesso às redes sociais

\begin{tabular}{|c|c|c|c|c|c|c|}
\hline $\begin{array}{l}\text { Quanto à frequência da } \\
\text { conexão nas redes } \\
\text { sociais... }\end{array}$ & $\begin{array}{l}\text { Rara- } \\
\text { mente }\end{array}$ & $\begin{array}{l}\text { Ocasional- } \\
\text { mente }\end{array}$ & $\begin{array}{l}\text { Frequente- } \\
\text { mente }\end{array}$ & $\begin{array}{l}\text { Geral- } \\
\text { mente }\end{array}$ & Sempre & $\begin{array}{l}\text { Não } \\
\text { sei/Não } \\
\text { se } \\
\text { aplica }\end{array}$ \\
\hline 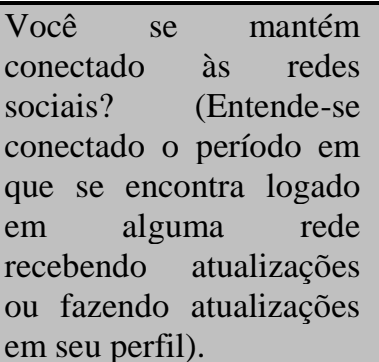 & $19,4 \%$ & $20,1 \%$ & $19,4 \%$ & $13,3 \%$ & $17,2 \%$ & $10,6 \%$ \\
\hline $\begin{array}{l}\text { Você costuma deixar de } \\
\text { lado tarefas de casa ou do } \\
\text { trabalho para conectar-se } \\
\text { a suas redes? }\end{array}$ & $56,3 \%$ & $23,1 \%$ & $2,0 \%$ & $1,9 \%$ & $0,2 \%$ & $16,5 \%$ \\
\hline $\begin{array}{l}\text { Você deixa de realizar } \\
\text { atividades de lazer para } \\
\text { ficar conectado às redes } \\
\text { sociais? }\end{array}$ & $66,7 \%$ & $11,9 \%$ & $3,1 \%$ & $0,9 \%$ & $0,0 \%$ & $17,4 \%$ \\
\hline $\begin{array}{l}\text { Você mantém contato } \\
\text { com amigos pelas redes } \\
\text { sociais e nano } \\
\text { pessoalmente? }\end{array}$ & $22,6 \%$ & $35,5 \%$ & $23,1 \%$ & $8,5 \%$ & $2,0 \%$ & $8,3 \%$ \\
\hline
\end{tabular}

Fonte: Dados da pesquisa/2016.

Dentre os entrevistados, $23,1 \%$ dos respondentes afirmam que mantém contato com amigos pelas redes sociais de forma frequente e $35,5 \%$ ocasionalmente, mantendo um contato on-line. As redes sociais proporcionam que os indivíduos criem perfis estabelecendo e mantendo conexões (AMARAL, TESTA E
LUCIANO, 2013) e é possível que existam interações que visem somar e construir um determinado laço social (RECUERO, 2011).

Observa-se que apenas $13,3 \%$ dos entrevistados responderam que geralmente ficam conectados as redes sociais e ainda 
$17,2 \%$ que sempre estão conectados. E a grande maioria respondeu que raramente deixa de lado tarefas de casa ou de realizar atividades de lazer para ficar conectado, $56,3 \%$ e $66,7 \%$ respectivamente. $\mathrm{O}$ acesso à Internet, segundo Soda e Zaheer (2012), se torna o principal relacionamento na vida da pessoa, e pode-se tornar um grande problema, contudo a pesquisa revela que o usuário não se mantém conectado de forma constante, ou talvez não perceba este acesso como frequente, apenas como ocasional.

Embora não seja possível destacar um uso excessivo por parte dos usuários, na Tabela 12 verifica-se a concordância sobre a utilização das redes sociais.

Tabela 12 - $\mathrm{O}$ uso de redes sociais e seus impactos

\begin{tabular}{|c|c|c|c|c|c|c|}
\hline $\begin{array}{l}\text { Quanto à utilização das } \\
\text { redes sociais, você } \\
\text { concorda que... }\end{array}$ & $\begin{array}{l}\text { Discordo } \\
\text { totalmente }\end{array}$ & $\begin{array}{l}\text { Discordo } \\
\text { parcialmente }\end{array}$ & Concordo & $\begin{array}{l}\text { Concordo } \\
\text { parcialmente }\end{array}$ & $\begin{array}{l}\text { Concordo } \\
\text { totalmente }\end{array}$ & $\begin{array}{l}\text { Não } \\
\text { sei/Não } \\
\text { se aplica }\end{array}$ \\
\hline $\begin{array}{l}\mathrm{O} \text { uso excessivo pode } \\
\text { tornar as pessoas } \\
\text { dependentes? }\end{array}$ & $2,4 \%$ & $3,9 \%$ & $28,9 \%$ & $24,0 \%$ & $39,3 \%$ & $1,5 \%$ \\
\hline $\begin{array}{l}\text { As redes sociais estão } \\
\text { afetando os usuários, } \\
\text { interferindo em suas } \\
\text { atividades rotineiras? }\end{array}$ & $1,9 \%$ & $9,2 \%$ & $29,3 \%$ & $28,6 \%$ & $29,4 \%$ & $1,6 \%$ \\
\hline $\begin{array}{l}\text { A utilização de redes } \\
\text { sociais pode atrapalhar o } \\
\text { desempenho no ambiente } \\
\text { organizacional? }\end{array}$ & $3,9 \%$ & $13,4 \%$ & $28,9 \%$ & $28,2 \%$ & $23,3 \%$ & $2,3 \%$ \\
\hline $\begin{array}{l}\text { As redes sociais estão } \\
\text { ligadas diretamente ao } \\
\text { emocional das pessoas? }\end{array}$ & $2,9 \%$ & $10,4 \%$ & $32,7 \%$ & $26,4 \%$ & $23,1 \%$ & $4,5 \%$ \\
\hline $\begin{array}{l}\text { Os usuários preferem as } \\
\text { amizades on-line às off- } \\
\text { line? (Entende-se por on- } \\
\text { line as amizades apenas } \\
\text { nas redes sociais e off-line } \\
\text { as amizades fora da } \\
\text { Internet) }\end{array}$ & $14,6 \%$ & $28,7 \%$ & $19,1 \%$ & $24,8 \%$ & $7,1 \%$ & $5,7 \%$ \\
\hline
\end{tabular}

Fonte: Dados da pesquisa/2016.

Nesta tabela buscou-se avaliar a concordância do usuário quanto à utilização da rede social em excesso, podendo gerar alguma dependência. Dos respondentes, $39,3 \%$ dos respondentes concordaram totalmente que o uso excessivo pode tornar as pessoas dependentes, $29,3 \%$ dos respondentes concordaram que o uso de redes sociais afeta aos usuários interferindo em suas atividades rotineiras. Ainda, observa-se que $32,7 \%$ dos respondentes concordam ainda que as redes sociais estão ligadas diretamente ao emocional das pessoas.

Percebe-se que o uso excessivo pode impactar no usuário, refletindo no seu 
desempenho e em seu emocional. Essa utilização não se trata de exibição da vida particular e sim do cotidiano e das histórias de pessoas (KOMESU, 2010), pois compartilhar histórias lhes dá uma posição de destaque, o que permite agitar o emocional e a autoestima das pessoas.

Abordados sobre a utilização de redes sociais, que pode atrapalhar $\mathrm{o}$ desempenho no ambiente organizacional, $28,2 \%$ dos respondentes concordam parcialmente e $23,3 \%$ dos respondentes concordam totalmente que este uso pode atrapalhar. Constata-se que somente $13,4 \%$ dos respondentes discordam parcialmente que o uso possa atrapalhar no desempenho organizacional. Destaca-se que, embora os usuários avaliem o seu grau de concentração e o seu desempenho como bons, mesmo utilizando redes sociais, acredita-se que este uso pode atrapalhar o desempenho, demonstrando que os usuários têm a percepção de que este uso precisa ser moderado. A inserção em redes é determinante para o compartilhamento da informação e do conhecimento, visto que estes espaços valorizam $\mathrm{o}$ compartilhamento de informações e podem auxiliar na construção do conhecimento, contudo esta utilização precisa ser consciente e moderada (CRUZ, 2009; CHRISTOFIDES; MUISE; DESMARAIS,
2009; HAHN; SCHERER; BASSO; SANTOS, 2016).

\subsection{0 uso de redes sociais e o desempenho organizacional: a visão de gestores e usuários}

Ao longo desta pesquisa é possível evidenciar que a percepção de usuários quanto à utilização de redes sociais no meio organizacional vem ao encontro da dos gestores. Observa-se, por exemplo, que o tempo relacionado ao acesso às redes sociais é similar entre os gestores e os usuários.

Dos respondentes considerados usuários, 35,4\% afirmam que raramente acessam seus perfis durante a jornada de trabalho, e $25,5 \%$ às vezes realizam o acesso. Por outro lado, 36,7\% dos gestores avalia que os usuários às vezes estão conectados. Neste caso gestor e usuário percebem que esses acessos não são frequentes, ocorrendo em muitas vezes por pouco tempo ao longo da jornada de trabalho.

Essa percepção do tempo de acesso apresenta um valor muito próximo entre ambos os grupos, podendo ser considerado novamente que gestores e usuários compartilham da mesma percepção quanto à utilização de redes sociais, sendo que $42,4 \%$ dos gestores percebem a utilização 
por menos de 1 hora por dia, e $50,7 \%$ dos respondentes usuários também avaliam este mesmo tempo.

Em relação ao desempenho de sua equipe, $39,8 \%$ dos gestores avaliaram como bom, e o grau de concentração também foi considerado em sua maioria dentro desta escala, obtendo $42,4 \%$ de respostas. A visão do usuário é mais positiva, pois avalia seu desempenho profissional como muito bom $(51,2)$, e $55,3 \%$ avaliam como muito bom o seu grau de concentração. Embora exista diferença, é possível verificar em ambos os grupos de respondentes que este uso não vem demonstrando impacto no desempenho de funcionários ou gestores.

Aplicando o teste Qui-Quadrado no grupo de respondentes gestores que possuem perfil em redes sociais e usuários de redes sociais, 758 respondentes, pode-se avaliar a frequência de uso entre gestores e usuários que possuem perfil. Verificam-se algumas variações na Tabela 13.

\section{Tabela 13 - Teste Qui-Quadrado}

\begin{tabular}{lllll}
\multicolumn{2}{l}{$\begin{array}{l}\text { Em geral, com que frequência costuma } \\
\text { acessar seu perfil nas redes sociais? }\end{array}$} & Gestores & Usuários & Total \\
\hline \multirow{2}{*}{ Muitas vezes ao dia } & Frequência & 92 & 354 & 446 \\
& $\%$ & $12,1 \%$ & $46,7 \%$ & $58,8 \%$ \\
Uma vez ao dia & Frequência & 59 & 186 & 245 \\
& $\%$ & $7,8 \%$ & $24,5 \%$ & $32,3 \%$ \\
\hline \multirow{2}{*}{ Uma vez por semana } & Frequência & 9 & 31 & 40 \\
& $\%$ & $1,2 \%$ & $4,1 \%$ & $5,3 \%$ \\
Quinzenalmente & Frequência & 1 & 2 & 3 \\
\hline \multirow{2}{*}{ Raramente } & $\%$ & $0,1 \%$ & $0,3 \%$ & $0,4 \%$ \\
& Frequência & 9 & 15 & 24 \\
\hline
\end{tabular}

Fonte: Dados da pesquisa/2016.

Dentre as variações existentes é possível destacar que o uso mais frequente entre os respondentes é dos usuários de redes sociais que não possuem cargo de gestão, sendo que 46,7\% afirmam acessar suas redes muitas vezes ao dia.
Outro dado importante, a maioria dos respondentes $(37,86 \%)$ que informaram ser permitido o acesso às redes sociais de forma livre no local de trabalho, não exercem cargo de gestão. Na Tabela 14 observa-se os resultados do teste Qui- 
Quadrado aplicado para verificar diferenças significativas entre respondentes gestores e usuários, avaliando a percepção de utilização de equipamentos com Internet no ambiente organizacional.

\section{Tabela 14 - Teste Qui-Quadrado}

É permitido que os funcionários utilizem Tipo de Respondente equipamentos móveis com acesso à Internet?

Tipo de

\begin{tabular}{|c|c|c|c|c|}
\hline equipamentos móveis com aces & â Inte & Gestores & Gestores & Respondente \\
\hline \multirow{2}{*}{ Não é permitido o uso } & Frequência & 32 & 116 & 148 \\
\hline & $\%$ & $4,2 \%$ & $15,3 \%$ & $19,5 \%$ \\
\hline \multirow{2}{*}{$\begin{array}{l}\text { Sim, livremente no local e horário } \\
\text { de trabalho }\end{array}$} & Frequência & 79 & 287 & 366 \\
\hline & $\%$ & $10,4 \%$ & $37,9 \%$ & $48,3 \%$ \\
\hline \multirow{2}{*}{$\begin{array}{l}\text { Sim, mas apenas em horários } \\
\text { definidos }\end{array}$} & Frequência & 59 & 185 & 244 \\
\hline & $\%$ & $7,8 \%$ & $24,4 \%$ & $32,2 \%$ \\
\hline
\end{tabular}

Fonte: Dados da pesquisa/2016.

As diferenças significativas entre a percepção de gestores e usuários também ocorrem no que se refere à utilização e acesso de redes sociais no ambiente organizacional. Destaca-se também que ambos entendem que a utilização sem medida pode vir a impactar no desempenho da equipe. Christofides, Muise e Desmarais (2009) ressaltam que o número de relacionamentos através da utilização das mídias sociais tem se tornado cada vez mais crescente. A constatação dos autores só confirma o que se percebe no cotidiano das relações. Isso leva à necessidade premente de uma maior conscientização de usuários e gestores quanto ao correto uso de equipamentos de acesso às redes sociais no ambiente de trabalho.
Como mencionam Olson e Boyer (2005) e Hall (2012), as TICs são elementos constitutivos da sociedade contemporânea, tendo proporcionado às organizações um desempenho mais eficaz em todas as suas atividades (OLSON; BOYER, 2005; SAMBHARYA; KUMARASWAMY; BANERJEE, 2005). Nessa esteira, as redes sociais, em muitos casos, são fortes aliadas das organizações na conquista de seu mercado consumidor. Como referem Cross, Borgatti e Parker (2002), o número de empresas que utiliza essas redes cresce significativamente a cada ano. No entanto, assim como pode constituir-se em importante ferramenta de trabalho, o uso irrestrito de redes sociais em horário e no ambiente de trabalho pode gerar problemas 
de desempenho e dispersões, já que o acesso através dos dispositivos móveis impede o controle por parte da organização.

\section{CONSIDERAÇÕES FINAIS}

O objetivo do artigo foi verificar a percepção de gestores quanto à utilização das redes sociais por suas equipes, bem como avaliar a interferência destas no ambiente de trabalho, a partir da avaliação do usuário. Para isso, utilizou-se como público respondente 779 alunos de uma IES localizada na região metropolitana de Porto Alegre/RS, acessados por meio de uma survey, com abordagem quantitativa.

As redes sociais estão cada vez mais presentes nas organizações, e esse crescimento se dá devido ao avanço das TICs e da Internet. Com base na aplicação da pesquisa com gestores e usuários, foi possível identificar algumas influências da utilização de redes sociais no ambiente de trabalho. Enquanto os gestores avaliam que 0 acesso às redes sociais impacta no desempenho dos funcionários, os subordinados julgam o uso como algo normal, que ocorre de forma esporádica, na maioria das vezes.

Quanto à influência do uso das redes sociais sobre o desempenho dos usuários, percebe-se - nas respostas tanto de gestores quanto de usuários - que o acesso às redes sociais não impacta no desempenho e desenvolvimento profissional.

Tinha-se como pressuposto a existência de grande influência das redes sociais no ambiente organizacional e acreditava-se que os usuários passam muito tempo acessando redes de comunicação em seus dispositivos móveis, em detrimento da realização de tarefas de sua responsabilidade funcional. Contudo, entre os respondentes, constatou-se um resultado diferente: os gestores percebem que o acesso às redes sociais, durante a jornada de trabalho, não é frequente; embora ocorra, não interfere no desempenho do funcionário.

Também na percepção dos usuários, o acesso, mesmo realizado nos computadores da empresa ou através de seus dispositivos móveis, não apresenta influência negativa no cumprimento das metas e objetivos da organização. Isso corrobora a ideia de Rushkoff (2012) de que, com a evolução das TICs, o trabalhador passa a realizar multitarefas, buscando dar atenção a mais de uma coisa simultaneamente e atender rapidamente as tarefas executadas no dia a dia das empresas. Trata-se do perfil atribuído a uma geração de pessoas cada vez mais conectada, seja em cargos de gestão ou de execução. 
Diante disso, observa-se que o acesso às redes sociais no ambiente de trabalho, para o grupo pesquisado, não traz reflexos negativos no desempenho do usuário. Entretanto, salienta-se que os gestores precisam manter-se atentos aos sinais emitidos por suas equipes, pois como o acesso à Internet está em todo lugar - o ingresso nas redes sociais pode não representar hoje um impacto na organização, mas é algo que tem demonstrado notável crescimento e pode, em algum momento, refletir-se no resultado da equipe e da organização. Não se deve ignorar o impacto dessas redes em seu meio de trabalho (BARNES; BARNES, 2009).

As principais limitações desta pesquisa referem-se à amostra, constituída de um grupo de respondentes com grau de formação diferenciado (alunos de cursos de graduação e pós-graduação) e maior facilidade de acesso inclusive a redes móveis. A escolaridade dos respondentes pode ter exercido influência em suas respostas, já que podem ter trabalhos mais qualificados, em organizações com políticas e práticas de gestão diferenciadas. Os próprios gestores, ao responder as questões, também podem ser influenciados indiretamente pelo fato de estarem em um ambiente diferenciado. Para estudos futuros, sugere-se considerar organizações específicas, como comércio e indústria, visando atingir um público maior. 


\section{REFERÊNCIAS}

AKHTER, M.; SIDDIQUE, M. N.; MASUM, A. L. Analysis of social network and its effect on job satisfaction and employee performance. ASA University Review, v. 5, n. 1, p.195-207, 2011.

ALBARRACÍN, Edgar Julián; Gálvez; ERAZO, Sandra Cristina Riascos; PALACIOS, Fred Contreras. Influencia de las tecnologías de la información y comunicación en el rendimiento de las micro, peque nas y medianas empresas colombianas. Estudios Gerenciales 30 (2014) 355364.

ALMEIDA, C.C. Novas tecnologias e interatividade: além das interações mediadas. DataGramaZero: Revista de Ciência da Informação, v.4, n.4, 2003. Disponível em: <http://www.dgz.org.br/ago03/Art_01.htm>. Acesso em: 23 de setembro de 2009.

AMARAL, Henrique Gonçalves; TESTA, Maurício Gregianin; LUCIANO, Edimara Mezzomo. A formação de capital social através de redes sociais na Internet: um estudo entre estudantes universitários. $37^{\circ}$ Encontro da ANPAD. Rio de Janeiro/ RJ - 07 a 11 setembro de 2013.

ASSUMPÇÃO, Maria Rita Pontes. Reflexão para Gestão tecnológica em Cadeias de suprimento. GESTÃO \& PRODUÇÃO, v.10, n.3, p.345-361, dez. 2003.

BAILEY, K.; FRANCIS, M. Managing information flows for improved value chain performance. International Journal of Production Economics, v.111, n. 1, p. 2-12, 2008.

BARNES, N. D.; BARNES, F. R. Equipping your organization for the social networking game. Information Management Journal, v. 43, n. 6, 2009.

BESSI, Vania Gisele; GRISCI, Carmem Ligia Iochins. Trabalho Imaterial e Resistência no Cotidiano do Trabalho. $30^{\circ}$ Encontro da ANPAD. Salvador/ BA - 23 a 27 setembro de 2006.

BESSI, Vania Gisele; PUFFAL, Daniel Pedro; SCHREIBER, Dusan; TONDOLO, Vilmar Antonio Gonçalves. As Tecnologias de Informação e Comunicação e sua Influência na Vivência Espaço-temporal de Trabalhadores Bancários. IV Encontro de Administração da Informação. Bento Gonçalves/ RS - 19 a 21 março de 2013.

BOBSIN, Débora; HOPPEN, Norberto. Estruturação de redes sociais virtuais em organizações: um estudo de caso. Revista de Administração, São Paulo, v.49, n.2, p.339-352, abr./maio/jun. 2014 
BORGES, Jussara; LESSA, Bruna; OLIVEIRA, Lídia. O papel dos sites de redes sociais nas estratégias comunicativas de organizações da sociedade civil de Salvador-Bahia-Brasil. Observatorio (OBS*) Journal, vol.8 - n³ (2014), 183-203

BROADBENT, M.; WEILL, P. Management by maxim: how business and IT managers can create IT infrastructures. Sloan Management Review, v. 38, n. 3, p. 77-92, Spring, 1997.

CARR, N. Ten tips for reducing burgeoning IT costs. Director, p. 56-57. August 2007.

CARVALHO, Jaciara de Sá. Redes e Comunidades: Ensino-aprendizagem pela Internet. São Paulo. 2011.

CASTELLS, M. A sociedade em rede. A era da informação: Economia, sociedade e cultura. (Vol.1), São Paulo: Paz e Terra, 2000.

CHRISTOFIDES, Emily; MUISE, Amy; DESMARAIS, Serge. Information disclosure and control on Facebook: are they two sides of the same coin or two different processes?. Cyber Psychology \& Behavior, v. 12, n. 3, p. 341-345, 2009.

CROSS, Rob.; BORGATTI, S. P.; PARKER, A. Making Invisible Work Visible: using social network analysis to support strategic collaboration. California Management Review, v. 44, n. 2, p. 25-46, 2002.

CRUZ, June Alisson Westarb et al. - Redes sociais e organizacionais em administração. Curitiba: Juruá, 2009.

DONNA, Camila Uliana; SILVA, Alfredo Rodrigues Leite. Os usos do Facebook nas manifestações dos simbolismos organizacionais. REAd | Porto Alegre - Edição $79-\mathrm{N}^{\circ} 3-$ setembro/dezembro 2014 - p. 681-712

DOWNING, Douglas; CLARK, Jeffrey; FARIAS, Alfredo Alves de. Estatística aplicada. 1. ed. São Paulo, SP: Saraiva, 1999. xii, 455p. (Essencial) ISBN 85-02-2351-9

FOREST, Amanda L.; WOOD, Joanne V. When Social Networking Is Not Working Individuals With Low Self-Esteem Recognize but Do Not Reap the Benefits of Self-Disclosure on Facebook. Psychological Science, v. 23, n. 3, p. 295-302, 2012

FREUND, John E.; SIMON, Gary A. Estatística aplicada: economia, administração e contabilidade. 9. ed. Porto Alegre, RS: Bookman, 2000. vi, 404 p. ISBN 8573075317 
FREY, Klaus. Governança Urbana e Redes Sociais: o Potencial das Novas Tecnologias da Informação e Comunicação. Trabalho apresentado em: EnANPAD 2003. Disponível em: $<$ http://www.anpad.org.br/evento.php?acao=trabalho\&cod_edicao_subsecao=48\&cod_evento _edicao=7\&cod_edicao_trabalho=1995\#self $\geq$. Acesso em: 21 de setembro de 2014 .

FRIEDMAN, Thomas L. O mundo é plano: uma breve história do século XXI. Rio de Janeiro: Objetiva, 2007.

GULATI, Ranjay; SILVESTRI, Luciana. Brokerage spaces: how informal networks transform formal structure in the pursuit of complex tasks. Academy of Management Proceedings, 2013.

HAHN, Ivanete Schneider; SCHERER, Flavia Luciane; BASSO, Kenny; SANTOS, Marindia Brachak dos. Consumer Trust in and Emotional Response to Advertisements on Social Media and their Influence on Brand Evaluation. Brazilian Business Review, v.13, n.4, p.49-71, 2016

HALL, D. J. et al. Inter-organizational IT use, cooperative attitude, and inter-organizational collaboration as antecedents to contingency planning effectiveness. International Journal of Logistics Management, v. 23,n. 1, p. 50-76, 2012

HARVEY, D. (2001) Condição pós-moderna. São Paulo: Edições Loyola.

IBGE - Instituto Brasileiro de Geogradia e Estatística. Pesquisa Mensal de Emprego. 2014. Disponível em:

<ftp://ftp.ibge.gov.br/Trabalho_e_Rendimento/Pesquisa_Mensal_de_Emprego/fasciculo_indi cadores_ibge/2014/pme_201404pubCompleta.pdf>. Acesso em: 17 de junho de 2014.

JANNUZZI, Celeste Aída Sirotheau Corrêa; FALSARELLA, Orandi Mina; SUGAHARA, Cibele Roberta. Sistema de informação: um entendimento conceitual para a sua aplicação nas organizações empresariais. Perspectivas em Ciência da Informação, v.19, n.4, p.94-117, out./dez. 2014

LARIEIRA, Cláudio Luís Carvalho; ALBERTIN, Alberto Luiz. Um estudo sobre os fatores organizacionais que influenciam a gestão de portfólio de projetos de tecnologia da informação e comunicação. REAd | Porto Alegre - Edição 81 - № 2 - maio/agosto 2015 - p. 515-547.

MALHOTRA, Naresh K. Pesquisa de Marketing: uma orientação aplicada. Tradução de: Nivaldo Montingelli Jr. E Alfredo Alves de Farias. 3.ed. Porto Alegre: Bookman, 2001. 
MARQUES, E. Redes sociais e pobreza em São Paulo.Tese de livre-docência apresentada ao Departamento de Ciência Política da USP, 2006.

MITRA, S.; CHAYA, A. K. Analyzing cost-effectiveness of organizations: the impact of information technology spending. Journal of Management Information Systems, v. 13, n. 2, p. 29-57, 1996

OLLIER-MALATERRE, Ariane; ROTHBARD, Nancy; BERG, Justin. When worlds collide in cyberspace: How boundary work in online social networks impacts professional relationships. Academy of Management Review, v.38, n.4, p.645-669 2013.

OLSON, J.R.; BOYER, K.K. Internet ticketing in a not-for-profit, service organization: building customer loyalty. International Journal of Operations \& Production Management, v. 25, n. 1, p. 74-92, 2005.

PINHEIRO, Alessandro de Orlando Maia; TIGRE, Paulo Bastos. Proposta de investigação sobre o uso de software no suporte à inovação em serviços. ERA, São Paulo, V. 55, n. 5, setout 2015, p.578-592.

PRODANOV, Cleber Cristiano; FREITAS, Ernani Cesar de. Metodologia do trabalho científico: métodos e técnicas da pesquisa e do trabalho acadêmico. Novo Hamburgo, RS: Feevale, 2009.

RECUERO, Raquel. Redes Sociais na Internet. 2a Ed - Porto Alegre: Sulina, 2011.

REICHERT, Kátia Cibele. Uso de tecnologias da informação e comunicação para a legitimação e preservação da imagem organizacional: um estudo de caso na indústria de calçados West Coast Ltda. 2008. 65 f. Monografia (Conclusão do Curso de Comunicação Social - Habilitação em Relações Públicas) - Feevale, Novo Hamburgo-RS, 2008.

ROSA, Helaine Abreu. Comunicação, Mercado e Mundo Virtual: Tendências para a próxima década. Anais do II Encontro ESPM de Comunicação e Marketing, São Paulo 6, 7 e 8 de novembro de 2007.

ROSA, Mario. A reputação na velocidade do pensamento: a Imagem e a Ética na Era Digital. São Paulo: Geração Editorial, 2006.

RUSHKOFF, Douglas. As 10 questões essenciais da era digital: programe seu futuro para não se programado por ele. São Paulo, SP. 2012. 
SAMBHARYA, R. B.; KUMARASWAMY, A.; BANERJEE, S. Information technologies and the future of the multinational enterprise. Journal of International Management, v. 11, n. 2, p. 143-161, 2005.

SEBRAE - Serviço Brasileiro de Apoio às Micro e Pequenas Empresas. Disponível em:

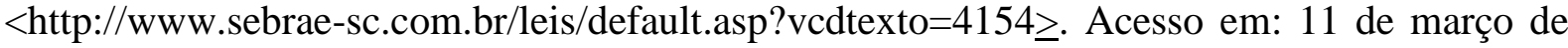
2015.

SIQUEIRA, Ethevaldo. 2015 Como Viveremos: o Futuro na visão de 50 famosos cientistas e futurologistas do Brasil e do Mundo. São Paulo: Saraiva, 2005.

SODA, Giuseppe; ZAHEER, Akbar. A network perspective on organizational architecture: performance effects of the interplay of formal and informal organization. Strategic Management Journal, v. 33, n. 6, p. 751-771, 2012.

TELLES, André. A Revolução das Mídias Sociais. Cases, Conceitos, Dicas e Ferramentas. São Paulo: M.Books, 2010

TIGRE, Paulo Bastos; NORONHA, Vitor Branco. Do mainframe à nuvem: inovações, estrutura industrial e modelos de negócios nas tecnologias da informação e da comunicação. Revista de Administração, São Paulo, v.48, n.1, p.114-127, jan./fev./mar. 2013

VENKATRAMAN, N. Beyond outsourcing: managing IT resource as a value center. Sloan Management Review, v. 38, n. 3, p. 51-64, 1997.

YIN, Robert K. Estudo de caso: planejamento e métodos. 2. ed. Porto Alegre, RS: Bookman, 2001.

YOUNG, Kimberly S...[et al.]; Dependência de Internet: Manual e Guia de Avaliação e Tratamento. Porto Alegre, RS: Artme, 2011. 